\title{
Skin temperature and reproductive condition in wild female chimpanzees
}

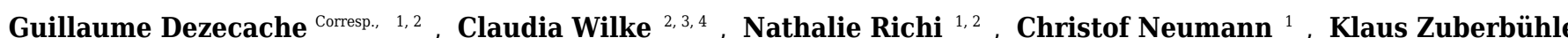
2,3

1 Institute of Biology, Université de Neuchâtel, Neuchâtel, Switzerland

2 Budongo Conservation Field Station, Masindi, Uganda

3 School of Psychology and Neuroscience, University of St. Andrews, Fife, United Kingdom

4 Department of Psychology, University of York, York, United Kingdom

Corresponding Author: Guillaume Dezecache

Email address: guillaume.dezecache@gmail.com

Infrared thermal imaging has emerged as a valuable tool in veterinary medicine, in particular for evaluating reproductive processes. Here, we explored differences in skin temperature of twenty female chimpanzees in Budongo Forest, Uganda, four of which were pregnant during data collection. Based on previous literature in other mammals, we predicted increased skin temperature of maximally swollen reproductive organs of nonpregnant females when approaching peak fertility. For pregnant females, we made the same prediction because it has been argued that female chimpanzees have evolved mechanisms to conceal pregnancy, including swellings of the reproductive organs, conspicuous copulation calling, and solicitation of male mating behaviour, to decrease the infanticidal tendencies of resident males by confusing paternity. For non-pregnant females, we found slight temperature increases towards the end of the swelling cycles but no significant change between the fertile and non-fertile phases. Despite their different reproductive state, pregnant females had very similar skin temperature patterns compared to non-pregnant females, suggesting little potential for males to use skin temperature to recognise pregnancies, especially during maximal swelling, when ovulation is most likely to occur in non-pregnant females. We discuss this pattern in light of the concealment hypothesis, i.e., that female chimpanzees have evolved physiological means to conceal their reproductive state during pregnancy. 
1 Skin temperature and reproductive condition in wild female chimpanzees

2 Guillaume Dezecache ${ }^{1,2}$, Claudia Wilke ${ }^{2,3,4}$, Nathalie Richi ${ }^{1,2}$, Christof Neumann ${ }^{1 *}$ \& Klaus 3 Zuberbühler ${ }^{1,2,3 *}$

4 Institute of Biology, University of Neuchâtel, Neuchâtel, Switzerland; ${ }^{2}$ Budongo Conservation

5 Field Station, Masindi, Uganda; ${ }^{3}$ School of Psychology and Neuroscience, University of St

6 Andrews, Fife, Scotland, United Kingdom; ${ }^{4}$ Department of Psychology, University of York,

7 York, United Kingdom

8 *equal contribution

9 Corresponding author: Guillaume Dezecache guillaume.dezecache@gmail.com 


\section{ABSTRACT}

12 Infrared thermal imaging has emerged as a valuable tool in veterinary medicine, in particular for

13 evaluating reproductive processes. Here, we explored differences in skin temperature of twenty

14 female chimpanzees in Budongo Forest, Uganda, four of which were pregnant during data

15 collection. Based on previous literature in other mammals, we predicted increased skin

16 temperature of maximally swollen reproductive organs of non-pregnant females when

17 approaching peak fertility. For pregnant females, we made the same prediction because it has

18 been argued that female chimpanzees have evolved mechanisms to conceal pregnancy, including

19 swellings of the reproductive organs, conspicuous copulation calling, and solicitation of male

20 mating behaviour, to decrease the infanticidal tendencies of resident males by confusing

21 paternity. For non-pregnant females, we found slight temperature increases towards the end of

22 the swelling cycles but no significant change between the fertile and non-fertile phases. Despite

23 their different reproductive state, pregnant females had very similar skin temperature patterns

24 compared to non-pregnant females, suggesting little potential for males to use skin temperature

25 to recognise pregnancies, especially during maximal swelling, when ovulation is most likely to

26 occur in non-pregnant females. We discuss this pattern in light of the concealment hypothesis,

27 i.e., that female chimpanzees have evolved physiological means to conceal their reproductive

28 state during pregnancy. 


\section{INTRODUCTION}

Infrared thermal imaging (IRT) has emerged as a promising tool for studying animal behaviour. For instance, research employing this methodology has helped cast light on affective processing in a variety of species, including macaques (Macaca mulatta) (Nakayama et al., 2005; Kuraoka \& Nakamura, 2011; Ioannou, Chotard \& Davila-Ross, 2015), chimpanzees (Pan troglodytes) (Kano et al., 2016; Dezecache et al., 2017) and dogs (Canis lupus familiaris) (Travain et al., 2015; Riemer et al., 2016; Travain et al., 2016). In these studies, IRT has been used to detect changes in emissivity of the skin caused by shifts in blood flow at the body surface, a physiological process controlled by the autonomic nervous system (see Ioannou, Gallese \& Merla, 2014 for a comprehensive review). One important asset of this technique is its noninvasive character, since measurements can be made at a reasonable distance from free-ranging animals and without hindering their on-going natural behaviour.

IRT has also been used as a non-invasive technique to study reproductive processes of animals (Cilulko et al., 2013). For example, Hilsberg-Merz (2008) noticed that female Asian elephants (Elephas maximus) and Black rhinoceroses (Diceros bicornis) showed increased surface temperature in the area of their reproductive organs during oestrus, a pattern associated with increased attractiveness to males. In pigs, vulvar skin temperatures were higher during oestrus compared to dioestrus (Sykes et al., 2012), a pattern related to increased blood flow towards the vulva due to oestrogen secretion in the ovarian follicles (Stelletta et al., 2013). Heightened temperature of the area of the reproductive organs can be used as a tool to detect oestrus in cows, with vulva temperature peaks around 24 hours before ovulation, followed by a slight decrease towards ovulation (Talukder et al., 2014). Furthermore, it has been suggested that thermo- 
53 reception may constitute a sensory strategy used by males in mammal species in order to detect

54 ovulation in females (Hilsberg-Merz, 2008), possibly in conjunction with other cues.

55

56

57

58

In sum, most current research using IRT has been performed on domestic and farm mammals, usually in the context of veterinary diagnosis (Cilulko et al., 2013), with only little systematic use in studying natural patterns, including sexual behaviour.

Here, we were interested in the skin temperature of wild female chimpanzees (Pan troglodytes) throughout the swelling cycle. The swelling cycle can be defined as the cyclical change during which a female's anogenital region gets progressively swollen and increases in size before reaching maximal tumescence, followed by detumescence, whereby the swelling area shows a rapid decrease in size and the skin becomes loose (Wallis, 1992; Deschner et al., 2004). In chimpanzees and other catarrhine species living in multi-male societies, females tend to develop exaggerated anogenital swellings during the periovulatory phase of their menstrual cycles (Nunn, 1999). There has been considerable debate on the biological function of exaggerated swellings, particularly in regard to whether swelling size, or tumescence, constitutes a reliable indicator of fertility. In chimpanzees, males show most interest in females during maximal tumescence (Wallis, 1992; Deschner et al., 2004) when ovulation is most likely to occur (Deschner et al., 2004). Gradual swelling tumescence is caused by increased oestrogen concentrations, while its sudden decrease is caused by increased progesterone secretion (Graham et al., 1972; Emery \& Whitten, 2003; Emery Thompson, 2005). However, swelling size is only a probabilistic indicator of fertility in chimpanzees, because maximal swelling can last up to 21 days with a mean of about 13 days and thus maximal tumescence may exceed the phase of peak fertility (Emery Thompson, 2005). This has been interpreted as an evolved female strategy to prolong the period 
76 of sexual attractiveness and, by increasing the number of copulations with different males, to

77 confuse paternity (Nunn, 1999; Alberts \& Fitzpatrick, 2012). Such a strategy is adaptive in 78 species where males commit infanticide, as is commonly observed across chimpanzee 79 communities (Williams et al., 2008; Goodall, 1986; Nishida \& Kawanaka, 1985; Watts \& 80 Mitani, 2000; Wilson et al., 2014).

82 As a first step, we were interested in whether the period of maximum tumescence, if compared to 83 earlier phases, can be identified by a unique temperature profile. In a second step, we were 84 interested in the temperature profiles of pregnant females, who have been suggested to conceal their gestation in an attempt to remain attractive to males (Wallis, 1982). Pregnant chimpanzee

86 females continue to be sexually active and display sexual swellings despite being no longer able 87 to conceive. It has been suggested that the maximal anogenital swelling during pregnancy may 88 account for one fourth of the total time female chimpanzees display maximal tumescence during their reproductive lifetime (Wallis \& Goodall, 1993). Pregnant females are, in some instances, even more sexually active than non-pregnant females (Wallis, 1982). One functional explanation

91 of this behavioural pattern is that pregnant females attempt to confuse paternity in the males of their group, which may lower the infanticidal tendencies of males once an infant is born (Wallis $93 \&$ Goodall, 1993).

Based on these findings, we hypothesised that variation in skin temperature may provide cues about the three main reproductive stages of a female, that is to say, pregnancy, oestrus, nonoestrus. However, based on the literature reviewed, female chimpanzees appear to have evolved ways to conceal their true reproductive stage, particularly pregnancy, but also the exact time of 
99 ovulation (Townsend, Deschner \& Zuberbühler, 2011). If males perceive changes in skin

100 temperature, then selection should favour individuals with skin temperature profiles that do not

101 reveal their reproductive condition.

102 To address these hypotheses, we investigated skin temperature of female chimpanzees in the

103 Sonso community of Budongo Forest, Uganda. We inspected the thermal patterns of pregnant

104 and non-pregnant females to test the following predictions. First, for non-pregnant females, we 105 expected higher temperatures (particularly of the genital area) during the fertile phase (when

106 females show peak swelling sizes and when sexual proceptivity is highest [Wallis, 1992])

107 compared to non-fertile phases (when swellings are not maximally inflated and sexual

108 proceptivity is comparably lower [(Wallis, 1992]). This was expected because, in farm animals,

109 the skin temperature of the vulva can be influenced by oestrogen secretion through increased 110 blood flow (Stelletta et al., 2013).

111

112 Second, if pregnant females follow an evolved strategy to conceal their pregnancy when showing 113 sexual tumescence, we predicted similarity in skin temperature at maximum tumescence between 114 pregnant and non-pregnant females (when male mating efforts are typically concentrated, see 115 Wallis [1992]), compared to earlier swelling stages, when copulation is comparatively rarer and 116 ovulation unlikely.

\section{METHODS}

119 Ethical statement Permission to conduct the study was granted by the Ugandan Wildlife 120 Authority (UWA) (UWA/TDO/33/02) and the Uganda National Council for Science and 
121 Technology (UNCST) (NS-475). Ethical approval was given by the University of St Andrews'

122 ethics committee.

123 Study site The study was carried out in the Budongo Forest Reserve, a moist semi-deciduous

124 tropical forest in western Uganda, covering $428 \mathrm{~km}^{2}$ at an altitude of $1,100 \mathrm{~m}$, between $1^{\circ} 35^{\prime}$

125 and $1^{\circ} 55^{\prime} \mathrm{N}$ and $31^{\circ} 08^{\prime}$ and $31^{\circ} 42^{\prime} \mathrm{E}$ (Eggeling, 1947). Data were collected from the

126 Sonso community between November 2011 and May 2012, and between August 2013 and June

127 2014. Habituation of this community to humans began in 1990, with the majority of individuals

128 (approximate $\mathrm{N}=70$ ) well habituated to human observers at the time of the study (Reynolds, 129 2005).

130

131 Materials Surface skin temperature measurements were taken with a Testo (881-2) thermal 132 imager, which operates between 8 and $14 \mu \mathrm{m}$ with a thermal sensitivity of $<80 \mathrm{mK}$ at $30^{\circ} \mathrm{C}$. 133 Emissivity was set at 0.98, a value typically used for human skin (Steketee, 1973). A telephoto 134 lens was used for all images $\left(9^{\circ} \times 7^{\circ} / 0.5 \mathrm{~m}\right)$. The device emits no light or sound and is thus 135 ideal for working with wild animals.

Pregnancy status We initially used HCG pregnancy tests (which respond to the presence of $>25$ $\mathrm{mI} \mathrm{U} / \mathrm{ml}$ human chorionic gonadotropin in the urine, a hormone produced by the placenta about one week after fertilisation). We later decided to estimate pregnancy status depending on the presence or absence of offspring up to 229 days after the recording was taken (assuming a mean gestation period of 229 days in chimpanzees [Reynolds, 2005]). This was done because it was only possible to perform one or two pregnancy tests for each individual, over a short time frame, 
143 so it is possible that some females may have been pregnant temporarily before or after testing.

144 Additionally, a more recent pilot study suggested that HCG pregnancy tests are unreliable in

145 wild chimpanzees, with pregnant females testing negative around their fifth month of gestation

146 (Caroline Asiimwe, personal communication).

147 As we relied upon the presence/absence of offspring after the average gestation period of 148 chimpanzees, it is possible that some females we designated as 'not pregnant' may have been in 149 the early stages of pregnancy when thermal images were recorded, without carrying the 150 pregnancy to term. Stillbirths and miscarriages are difficult to distinguish in the wild (Courtenay 151 \& Santow, 1989) (but see Tutin [1975]). Studies in captivity indicate that miscarriages may

152 happen in around 8\% of the pregnancies (Courtenay, 1987) and fetal wastage (miscarriage and 153 stillbirths) may occur following 14\% of all conceptions (Littleton, 2005).

154 Thermography data collection Data collection took place between 07:00 and 16:30 local time.

155 On a given morning, a female was selected as the focal animal and followed throughout the day 156 with IRT photographs taken whenever the individual was in clear view, and photographs taken 157 of surrounding individuals ad libitum. Although we considered all females during data 158 collection, we later excluded 64 images of females with dependent infants ( $<4$ years). Although 159 some of them may have been cycling, we excluded them because of difficulties in determining 160 their reproductive status.

162 All sampled individuals (20 females, 4 of which were pregnant during parts of data collection) 163 were sufficiently tolerant to observer presence within $10 \mathrm{~m}$. Each body part (face, ears, nose, 164 hands and feet, and swelling/genitals) was sampled only once every half hour with females 165 contributing differently to the dataset (see Table 1). For an image to be taken, the focal had to be 
166 within a distance of $15 \mathrm{~m}$ (range: less than $1 \mathrm{~m}-15 \mathrm{~m})$ and less than $5 \mathrm{~m}$ above ground. They had to

167 be in unobstructed view, with a body part clearly visible to the observer and in dry conditions

168 (water alters the temperature and emissivity of skin) and not exposed to direct sunlight. Readings

169 were taken from body parts that were exposed and free of hair. For each image, we estimated the

170 distance to the focal individual (in metres). Ambient temperature and humidity data were

171 collected using an electronic recorder, as these may affect infra-red readings. Swelling

172 tumescence was determined by experienced field assistants from stage 0 (absence of tumescence)

173 to stage 4 (maximum tumescence) as judged by the degree of wrinkling (Furuichi, 1987)

174 (adapted for chimpanzees: Townsend et al. [2008]). Note that the field assistants were blind to

175 the aims and hypotheses of the study.

176 Image analysis Thermal images were analysed using the Testo IRSoft analysis software. A

177 polygon image selection tool was used on each image to select specific body parts of interest for

178 subsequent thermal analysis. For each selected region of interest, we obtained the mean

179 temperature (see Figure 1 for example). Two coders (GD and CW) performed the image 180 analysis. To test for inter-observer reliability, we examined measurements of $\mathrm{N}=408$ thermal 181 images taken by two coders. There was a mean difference of $0.15+/-0.43^{\circ} \mathrm{C}$ (mean difference 182 between the two sets of measurements +/- SD) between the two sets of measurements, with high 183 internal consistency (Cronbach's alpha, $\alpha=0.99$ ), suggesting that our method of calculating the 184 average temperature of an area of interest was consistent.

185 Statistical analysis We used a linear mixed model with Gaussian error structure and maximum 186 likelihood estimation to assess how swelling stage and pregnancy affected skin temperature of 187 female chimpanzees. In our initial model, we fitted the two-way interaction between swelling 188 stage and reproductive state. This also allowed us to specifically address the possibility that 
189 variation in temperature between swelling stages may show different patterns in pregnant and 190 non-pregnant females. In addition, we controlled for ambient temperature, humidity and distance

191 between camera and subject. Because some images allowed simultaneous measurement of 192 several body parts, we fitted image ID nested in subject ID as random intercept. In this way, we 193 also accounted for multiple measurements of the same female. We fitted body part as random 194 intercept and in addition, allowed the effects of swelling stage and pregnancy state on skin 195 temperature to vary between body parts by incorporating random slopes for these variables (Barr 196 et al., 2013). Ideally, we would have incorporated similar random slopes for female ID, thereby 197 allowing between subject variation in the effects of swelling and pregnancy on temperature. 198 Unfortunately, we had to forego this step because the resulting model structure was too complex 199 for our data set. Before model fitting, we inspected distributions of variables and transformed 200 them to achieve symmetric distributions (see Supplementary Information). In addition, we scaled

201 all numeric variables to mean=0 and standard deviation=1 (Schielzeth, 2010). We checked for 202 homogeneity and normality of model residuals visually and calculated variance inflation factors 203 (Fox \& Weisberg, 2010). Neither check indicated serious deviations from modelling assumptions. We then calculated Cook's distance as a measure for the influence of each single individual in our data set on our model results. Here we found a number of individuals with substantial influence on our results. Specifically, Cook's distance for all four females in our data 207 set that were pregnant during the study exceeded the critical threshold (c.f. Nieuwenhuis, te 208 Grotenhuis \& Pelzer [2012]). Furthermore, we tested full models against our null models (see 209 below) in a leave-one-out fashion to assess the potential influence of single females: we fitted the

210 full and null model with a data set from which one female was excluded per turn. Here, 211 exclusion of one female $(\mathrm{OK}$ - see Table 1$)$ led to the full model not being significant $(\mathrm{p}>0.05)$, 
212 although the signs of the parameter estimates remained unchanged. Despite this consistency in

213 the direction of our results, the interaction between swelling stage and pregnancy must be

214 interpreted with some caution, as their statistical significance hinges on one individual. However,

215 the signs of our major result concerning the differences between pregnant and non-pregnant

216 females remained consistent, regardless of which female we excluded.

217

218 To test the significance of our full model, we built an informed null model, which contained the 219 random effects structure as described above and the three control fixed effects (ambient 220 temperature, humidity, distance). We then tested our full model against this null model using a

221 likelihood ratio test (LRT, Dobson \& Barnett, 2008). Similarly, we tested the interaction by 222 comparing the model including the interaction (i.e. the full model) against a model without the 223 interaction (swelling stage and reproductive state as main effects only). We calculated marginal 224 and conditional $R^{2}$ following (Nakagawa \& Schielzeth, 2013) and (Johnson, 2014), using the 225 MuMIn package (Barton, 2016). We fitted all models in R 3.3.0 (R Core Team, 2016), using the 226 lme4 package (v. 1.1-12, Bates et al. [2015]).

227

228 From the existing literature (Hilsberg-Merz, 2008; Scolari et al., 2011; Sykes et al., 2012;

229 Talukder et al., 2014), we predicted an increase in temperature throughout the swelling cycle in 230 non-pregnant chimpanzees, with a peak temperature at full tumescence, in particular at the area 231 of the reproductive organs, when females are fertile. Second, and following the hypothesis that

232 female chimpanzees have evolved physiological and behavioural strategies to conceal 233 pregnancy, we predicted pregnant females to show similar patterns of skin temperature changes 234 at peak tumescence when the probability of conception is at its highest for non-pregnant females. 
236 To address the two predictions, we assessed skin temperature associated with swelling and 237 reproductive state, at various body parts, controlling for ambient temperature, humidity and 238 recording distance.

239

\section{RESULTS}

241 Our full model (containing swelling stage and reproductive state and their interaction plus the 242 control terms: distance, humidity and ambient temperature) was significantly different from the 243 null model (containing the control terms only) (LRT: $\chi^{2}{ }_{9}=19.48, \mathrm{p}=0.0214, R_{\mathrm{m}}^{2}=0.33, R_{\mathrm{c}}^{2}=$ 244 0.90, Table 2). Concerning our variables of interest - reproductive state and swelling stage - we

245 found that the model containing the interaction between the two was significantly different from 246 a model from which the interaction term was removed (LRT: $\left.\chi^{2}{ }_{4}=9.72, p=0.0455\right)$. Thus, our 247 results indicate that skin temperature showed greater variability in pregnant females $(\mathrm{N}=4)$ than 248 non-pregnant females $(\mathrm{N}=20)$. Generally, pregnant females had lower skin temperatures than 249 non-pregnant females when deflated and during smaller swelling stages (stages 0 - 2, Figure 2), 250 of less than $1^{\circ} \mathrm{C}$ overall. This pattern changed later in the cycle, with pregnant females having

251 higher skin temperature compared to non-pregnant females (stage 3, Figure 2), again with a 252 magnitude of less than $1{ }^{\circ} \mathrm{C}$. During maximum tumescence (swelling stage 4), temperatures of 253 non-pregnant and pregnant females appeared most similar compared to all other swelling stages. 254 This was true for all body parts measured (Figures 3 and 4).

256 Finally, and contrary to our predictions, we did not find a clear increase in temperature 257 throughout the swelling cycle (Figure 2), at the area of the reproductive organs and elsewhere 
258 (Figure 3). There was a modest increase in skin temperature between stages 1-2 and stages 3-4,

259 in both pregnant and non-pregnant females, in particular around (but not restricted to) the vulvar

260 area (Figure 3). Yet, we did not find a clear difference between the skin temperature at maximal

261 swelling (where female proceptivity is higher [Wallis, 1992]) and reduced swelling stages.

262 Finally, skin temperature seems comparable or even slightly higher during detumescence than at

263 maximum tumescence.

\section{DISCUSSION}

Our aim was to assess whether skin temperature may reveal the reproductive state of female chimpanzees, using IRT, a well-developed technique in veterinary medicine, with yet little application so far in the field of behavioural ecology. We compared wild female chimpanzees throughout their swelling cycle and predicted that (i) non-pregnant females should show higher skin temperature when oestral than when anoestral, as well as an increase in skin temperature (with maximal temperature at the end of the swelling cycle, particularly at the area of the reproductive organs), following previous observations in other species (Hilsberg-Merz, 2008;

273 Scolari et al., 2011; Sykes et al., 2012; Talukder et al., 2014). We also predicted that (ii) pregnant

274 females should approximately overlap with the temperature patterns exhibited by non-pregnant females, despite their radically different hormonal state at maximum swelling (stage 4) when males are sexually interested in them. This second prediction is based on the hypothesis that

277 pregnant females have evolved gestation concealing strategies, as they incur an adaptive 278 advantage in concealing pregnancy, to enhance the benefits of paternity confusion by 279 promiscuous mating as long as possible. 
281 Our results were consistent with the first prediction, by showing slightly higher temperatures of

282 the anogenital regions when transitioning from stages 1-2 to 3-4 (Figure 2), consistent with what

283 has been found in other mammal species (Hilsberg-Merz, 2008; Scolari et al., 2011; Sykes et al., 284 2012; Stelletta et al., 2013; Talukder et al., 2014). However, this pattern was true for most body

285 parts considered, not solely for the anogenital region (Figure 3). Although it is hard to directly 286 compare our results to previous studies using IRT because of different definitions and methods, 287 the differences we found in our results are of similar magnitudes (about $1^{\circ} \mathrm{C}$ ) compared to other 288 studies (Scolari et al., 2011; Sykes et al., 2012). In both human and non-human female primates, 289 skin colour and tone can change during the fertile period (Roberts et al., 2004; Dubuc et al., 290 2009), and such variation may be perceived by males (Higham et al., 2011). Variation in skin 291 colour, presumably caused by blood flow and associated temperature changes, may affect the 292 entire body, including the face, and not be restricted to the periovulatory area.

294 Regarding our second prediction, we found smaller changes in skin temperature in non-pregnant compared to pregnant females. Crucially, for stage 4, we observed more similar skin temperatures between pregnant and non-pregnant females, compared to the other swelling stages with the prediction that, during gestation, chimpanzee females approximate behavioural and physiological cues that characterise non-pregnant females, which functions to conceal their reproductive state. This could be part of an evolved strategy to deceive males by remaining sexually attractive to them and ultimately to confuse paternity and lower infanticide risk after parturition. Alternatively, the overlap in anogenital temperature could be the by-product of 303 physiological mechanisms involved in anogenital swelling. In the context of the concealment 
304 hypothesis, it is worth mentioning that pregnant females show less clear transitions between 305 swelling stages compared to non-pregnant females. Instead, swelling sizes appear to change 306 more erratically, and hence a probably simpler means for males would be to attend to gradation 307 of swelling changes. Previous work has already shown that females show irregular swelling 308 patterns during the early stages of pregnancy (Wallis \& Goodall, 1993).

310 Sexual swellings during pregnancy have also been reported in other non-human primates, such as 311 sooty mangabeys (Cercocebus atys) (Gordon et al., 1991) and Barbary macaques (Macaca 312 sylvanus) (Möhle et al., 2005), but in these species the swelling patterns between pregnant and non-pregnant females seem to differ. Whether males are responsive to non-monotonic changes in

314 swelling and, if so, whether this affects their mating behaviour and future infanticidal tendencies, 315 would be worth exploring.

317 The important question of whether temperature changes are perceivable by males remains 318 unresolved. In humans, thermal discrimination has been investigated in the domain of 319 psychophysics, using tasks where participants are presented with pairs of materials and 320 instructed to choose the cooler of two objects. Thermal discrimination varies with the nature and 321 size of contact sites as well as the baseline temperature of the skin around the contact site (Ho \& 322 Jones, 2006). Also, the rate and magnitude of temperature changes play a considerable role in the 323 discrimination of thermal increments (Jones \& Berris, 2002; Ho \& Jones, 2006). The thenar 324 eminence at the base of the thumb is one of the most sensitive body parts with reported thermal 325 discrimination of less than $0.1^{\circ} \mathrm{C}$ (Ho \& Jones, 2006). If chimpanzees possess temperature 
326 discrimination capacities similar to humans, then males should be able to perceive the

327 temperature changes reported in this study.

328

329 It is also worth mentioning that primate males almost certainly use additional signs to make

330 fertility assessments of females during their sexual swelling cycles, particularly olfactory signals

331 (Michael \& Zumpe, 1982). In humans (Homo sapiens), female body odour during highly fertile

332 days is preferred by males (Gildersleeve et al., 2012). In other primate species, olfactory cues

333 may also play a role (Ziegler et al., 1993; Converse et al., 1995; Clarke, Barrett \& Henzi, 2009),

334 but, to our knowledge, relevant systematic research in chimpanzees has not been conducted (Fox,

335 1982). Regarding visual signals, skin colour and tone can change during the fertile period in

336 human and non-human primate females (Roberts et al., 2004; Dubuc et al., 2009), and such

337 variation may be perceived by males (Higham et al., 2011). In humans, facial redness has been

338 linked to the vasodilatation caused by oestradiol (Jones et al., 2015), a pattern in blood flow

339 around the facial area that may be associated with increase in skin temperature. Finally, female

340 sexual behaviour itself can reveal the most fertile period of the swelling cycle (Engelhardt et al.,

341 2005). Future studies should also investigate whether non-pregnant vs. pregnant female

342 chimpanzees show reliable differences in those areas.

344 We acknowledge several limitations to our research. First, we did not find a clear increase in skin

345 temperature when comparing anogenital areas of females in fertile and non-fertile stages.

346 Second, only four pregnant females contributed to our dataset, so it would be important to

347 replicate these findings with a larger sample of pregnant females. Third, we did not collect any

348 hormonal data and were therefore unable to determine the point of likely ovulation. A validation 
349 study is necessary and would moreover be feasible in captive settings. Finally, we had no

350 behavioural data to show that males are directly responsive to changes in skin temperature, and

351 can be deceived by pregnant females who may have similar skin temperature profiles as fertile

352 individuals. Such behavioural data could have also helped to control for other potential factors

353 that may have affected skin temperature, such as the amount of physical activity when resisting

354 solicitations from males (Stumpf \& Boesch, 2005). Nevertheless, we consider it plausible that

355 males can be affected by pregnant females' skin temperature, mainly because shifts in blood

356 flow, and their corresponding changes in skin temperature, may affect skin colouration in the 357 face.

359 In sum, our data appear consistent with the prediction that, during gestation, chimpanzee females approximate skin temperature as well as behavioural and visual cues that characterise nonpregnant females. Yet, it is still possible that skin temperature does not constitute a deceptive signal in chimpanzees. Rather, skin temperature may simply be a by-product of the physiological mechanisms driving anogenital tumescence. Furthermore, we offer inconclusive evidence of a thermal pattern associated with fertility. Skin temperature seems to increase throughout the swelling cycle, but with no clear differences in skin temperature compared to when females are anoestral. Our research offers a tentative exploration of changes in skin temperature associated with fertility and pregnancy in wild female chimpanzees, which future research can build on, using IRT to tackle important questions in the field of behavioural ecology. 
371 We are grateful for comments from by Lydia Hopper, Katherine Cronin and two anonymous

372 reviewers. We thank the Uganda Wildlife Association and the Uganda National Council for

373 Science and Technology for permission to conduct the study. Our gratitude goes to Geoffrey

374 Muhanguzi, Caroline Asiimwe, Geresomu Muhumuza, Bosco Chandia and Sam Adue for their

375 support in the field. We further thank Cat Hobaiter, Roman Wittig, Dave Perrett, William

376 Paterson, Dominic McCafferty, Ross Whitehead, Amanda Hahn, Brittany Fallon and Zanna Clay

377 for helpful discussions and/or comments on the manuscript.

378

\section{REFERENCES}

380

381

382

383

384

385

386

387

388

389

390

391

392

393

Alberts SC., Fitzpatrick CL. 2012. Paternal care and the evolution of exaggerated sexual swellings in primates. Behavioral Ecology 23:699-706. DOI: 10.1093/beheco/ars052.

Barr DJ., Levy R., Scheepers C., Tily HJ. 2013. Random effects structure for confirmatory hypothesis testing: Keep it maximal. Journal of memory and language 68(3). DOI: 10.1016/j.jml.2012.11.001.

Bartoń K. 2017. MuMIn: Multi-Model Inference. Available at https://cran.rproject.org/web/packages/MuMIn/index.html

Bates, D. M., Mächler, M., Bolker, B. M. \& Walker, S. C. 2015. Fitting linear mixed-effects models using lme4. Journal of Statistical Software, 67:1-48. DOI: 10.18637/jss.v067.i01

Cilulko J., Janiszewski P., Bogdaszewski M., Szczygielska E. 2013. Infrared thermal imaging in studies of wild animals. European Journal of Wildlife Research 59:17-23. DOI: 10.1007/s10344-0120688-1

Clarke PMR., Barrett L., Henzi SP. 2009. What role do olfactory cues play in chacma baboon mating? American Journal of Primatology 71:493-502. DOI: 10.1002/ajp.20678. 
394 Converse LJ., Carlson AA., Ziegler TE., Snowdon CT. 1995. Communication of ovulatory state to mates

395

396

397

398

399

400

401

402

403

404

405

406

407

408

409

410

411

412

413

414

415

416

417

418

419 by female pygmy marmosets, Cebuella pygmaea. Animal Behaviour 49:615-621. DOI:10.1016/0003-3472(95)80194-4.

Courtenay J. 1987. Post-partum amenorrhoea, birth intervals and reproductive potential in captive chimpanzees. Primates 28:543-546. DOI:10.1007/BF02380869

Courtenay J., Santow G. 1989. Mortality of wild and captive chimpanzees. Folia Primatologica 52:167177. DOI:10.1159/000156395

Deschner T., Heistermann M., Hodges K., Boesch C. 2004. Female sexual swelling size, timing of ovulation, and male behavior in wild West African chimpanzees. Hormones and Behavior 46:204-215. DOI:10.1016/j.yhbeh.2004.03.013

Dezecache G., Zuberbühler K., Davila-Ross M., Dahl CD. 2017. Skin temperature changes in wild chimpanzees upon hearing vocalizations of conspecifics. Open Science 4:160816. DOI: 10.1098/rsos.160816.

Dobson AJ., Barnett A. 2008. An introduction to generalized linear models. Boca Raton, FL: CRC press.

Dubuc C., Brent LJ., Accamando AK., Gerald MS., MacLarnon A., Semple S., Heistermann M., Engelhardt A. 2009. Sexual skin color contains information about the timing of the fertile phase in free-ranging Macaca mulatta. International Journal of Primatology 30:777-789. DOI:10.1007/s10764-009-9369-7

Eggeling WJ. 1947. Observations on the Ecology of the Budongo Rain Forest, Uganda. Journal of Ecology 34:20-87. DOI: 10.2307/2256760.

Emery Thompson M. 2005. Reproductive endocrinology of wild female chimpanzees (Pan troglodytes schweinfurthii): methodological considerations and the role of hormones in sex and conception. American Journal of Primatology 67:137-158. DOI:10.1002/ajp.20174

Emery MA., Whitten PL. 2003. Size of sexual swellings reflects ovarian function in chimpanzees (Pan troglodytes). Behavioral Ecology and Sociobiology 54:340-351. DOI: 10.1007/s00265-003-06486 
420 Engelhardt A., Hodges JK., Niemitz C., Heistermann M. 2005. Female sexual behavior, but not sex skin

421

422

423

424

425

426

427

428

429

430

431

432

433

434

435

436

437

438

439

440

441

442

443

444

445 swelling, reliably indicates the timing of the fertile phase in wild long-tailed macaques (Macaca fascicularis). Hormones and Behavior 47:195-204. DOI:10.1016/j.yhbeh.2004.09.007

Fox GJ. 1982. Potentials for Pheromones in Chimpanzee Vaginal Fatty Acids. Folia Primatologica 37:255-266. DOI: 10.1159/000156036.

Fox J., Weisberg S. 2010. An R companion to applied regression. New York: Sage.

Furuichi T. 1987. Sexual swelling, receptivity, and grouping of wild pygmy chimpanzee females at Wamba, Zaire. Primates 28:309-318. DOI:10.1007/BF02381014

Gildersleeve KA., Haselton MG., Larson CM., Pillsworth EG. 2012. Body odor attractiveness as a cue of impending ovulation in women: Evidence from a study using hormone-confirmed ovulation. Hormones and Behavior 61:157-166. DOI: 10.1016/j.yhbeh.2011.11.005.

Goodall J. 1986. The chimpanzees of Gombe: Patterns of behavior. Cambridge, MA: Harvard University Press.

Gordon TP., Gust DA., Busse CD., Wilson ME. 1991. Hormones and sexual behavior associated with postconception perineal swelling in the sooty mangabey (Cercocebus torquatus atys). International Journal of Primatology 12:585-597. DOI: 10.1007/BF02547671.

Graham CE., Collins DC., Robinson H., Preedy JRK. 1972. Urinary levels of estrogens and pregnanediol and plasma levels of progesterone during the menstrual cycle of the chimpanzee: relationship to the sexual swelling. Endocrinology 91:13-24. DOI:10.1210/endo-91-1-13

Higham JP., Hughes KD., Brent LJN., Dubuc C., Engelhardt A., Heistermann M., Maestriperi D., Santos LR., Stevens M. 2011. Familiarity affects the assessment of female facial signals of fertility by free-ranging male rhesus macaques. Proceedings of the Royal Society of London B: Biological Sciences 278:3452-3458. DOI: 10.1098/rspb.2011.0052.

Hilsberg-Merz S. 2008. Infrared thermography in zoo and wild animals. In: Flower ME, Eric Miller R (eds) Zoo and Wild Animal Medicine Current Therapy, volume six. St Louis: Saunders, Elsevier, 20-33. DOI: 10.1016/B978-141604047-7.50006-3. 
446 Ho H-N., Jones LA. 2006. Contribution of thermal cues to material discrimination and localization.

447

448

449

450

451

452

453

454

455

456

457

458

459

460

461

462

463

464

465

466

467

468

469

470

Perception \& Psychophysics 68:118-128. DOI: 10.3758/BF03193662.

Ioannou S., Chotard H., Davila-Ross M. 2015. No strings attached: physiological monitoring of rhesus monkeys (Macaca mulatta) with thermal imaging. Frontiers in Behavioral Neuroscience 9. DOI: $10.3389 /$ fnbeh.2015.00160

Ioannou S., Gallese V., Merla A. 2014. Thermal infrared imaging in psychophysiology: potentialities and limits. Psychophysiology 51:951-963. DOI:10.1111/psyp.12243

Johnson PC. 2014. Extension of Nakagawa \& Schielzeth's R2GLMM to random slopes models. Methods in Ecology and Evolution 5:944-946. DOI:10.1111/2041-210X.12225

Jones LA., Berris M. 2002. The psychophysics of temperature perception and thermal-interface design. In: Proceedings 10th Symposium on Haptic Interfaces for Virtual Environment and Teleoperator Systems. HAPTICS 2002. 137-142. DOI: 10.1109/HAPTIC.2002.998951.

Jones BC., Hahn AC., Fisher CI., Wincenciak J., Kandrik M., Roberts SC., Little AC., DeBruine LM. 2015. Facial coloration tracks changes in women's estradiol. Psychoneuroendocrinology 56:29_ 34. DOI:10.1016/j.psyneuen.2015.02.021

Kano F., Hirata S., Deschner T., Behringer V., Call J. 2016. Nasal temperature drop in response to a playback of conspecific fights in chimpanzees: A thermo-imaging study. Physiology \& Behavior 155:83-94. DOI: 10.1016/j.physbeh.2015.11.029

Kuraoka K., Nakamura K. 2011. The use of nasal skin temperature measurements in studying emotion in macaque monkeys. Physiology \& Behavior 102:347-355. DOI:10.1016/j.physbeh.2010.11.029

Littleton J. 2005. Fifty years of chimpanzee demography at Taronga Park Zoo. American Journal of Primatology 67:281-298. DOI:10.1002/ajp.20185

Michael RP., Zumpe D. 1982. Influence of olfactory signals on the reproductive behaviour of social groups of rhesus monkeys (Macaca mulatta). Journal of Endocrinology 95:189-205. DOI: 10.1677/joe.0.0950189. 
471 Möhle U., Heistermann M., Dittami J., Reinberg V., Hodges J k. 2005. Patterns of anogenital swelling

472

473

474

475

476

477

478

479

480

481

482

483

484

485

486

487

488

489

490

491

492

493

494

495

size and their endocrine correlates during ovulatory cycles and early pregnancy in free-ranging barbary macaques (Macaca sylvanus) of Gibraltar. American Journal of Primatology 66:351-368. DOI: 10.1002/ajp.20161.

Nakagawa S., Schielzeth H. 2013. A general and simple method for obtaining R2 from generalized linear mixed-effects models. Methods in Ecology and Evolution 4:133-142. DOI:10.1111/j.2041210x.2012.00261.x

Nakayama K., Goto S., Kuraoka K., Nakamura K. 2005. Decrease in nasal temperature of rhesus monkeys (Macaca mulatta) in negative emotional state. Physiology \& Behavior 84:783-790. DOI:10.1016/j.physbeh.2005.03.009

Nieuwenhuis R., te Grotenhuis HF., Pelzer BJ. 2012. Influence. ME: tools for detecting influential data in mixed effects models. The R Journal 4(2):38-47.

Nishida T., Kawanaka K. 1985. Within-group cannibalism by adult male chimpanzees. Primates 26:274284. DOI: $10.1007 / \mathrm{BF} 02382402$.

Nunn CL. 1999. The evolution of exaggerated sexual swellings in primates and the graded-signal hypothesis. Animal Behaviour 58:229-246. DOI: 10.1006/anbe.1999.1159.

Reynolds V. 2005. The Chimpanzees of the Budongo Forest: Ecology, Behaviour, and Conservation. Oxford: Oxford University Press.

Riemer S., Assis L., Pike TW., Mills DS. 2016. Dynamic changes in ear temperature in relation to separation distress in dogs. Physiology \& Behavior 167:86-91.

DOI:10.1016/j.physbeh.2016.09.002

Roberts SC., Havlicek J., Flegr J., Hruskova M., Little AC., Jones BC., Perrett DI., Petrie M. 2004. Female facial attractiveness increases during the fertile phase of the menstrual cycle. Proceedings of the Royal Society of London. Series B: Biological Sciences 271:S270-S272. DOI: 10.1098/rsbl.2004.0174. 
496

497

498

499

500

501

502

503

504

505

506

507

508

509

510

511

512

513

514

515

516

517

518

519

Schielzeth H. 2010. Simple means to improve the interpretability of regression coefficients. Methods in Ecology and Evolution 1:103-113. DOI:10.1111/j.2041-210X.2010.00012.x

Scolari SC., Clark SG., Know RV., Tamassia M.A. 2011. Vulvar skin temperature changes significantly during estrus in swine as determined by digital infrared thermography. Journal of Swine Health and Production 19(3):151-155.

Steketee J. 1973. Spectral emissivity of skin and pericardium. Physics in Medicine and Biology 18:686. DOI:10.1088/0031-9155/18/5/307

Stelletta C., Vencato J., Fiore E., Gianesella M. 2013. Infrared thermography in reproduction, In: Luzi F., Mitchell M., Costa L.N., Redaelli V. (Eds.), Thermography: Current Status and Advances in Livestock Animals and in Veterinary Medicine. Brescia:A Cura Della, Brescia, Italy, 113-125.

Stumpf RM., Boesch C. 2005. Does promiscuous mating preclude female choice? Female sexual strategies in chimpanzees (Pan troglodytes verus) of the Taï National Park, Côte d'Ivoire. Behavioral Ecology and Sociobiology 57:511-524. DOI:10.1007/s00265-004-0868-4

Sykes DJ., Couvillion JS., Cromiak A., Bowers S., Schenck E., Crenshaw M., Ryan PL. 2012. The use of digital infrared thermal imaging to detect estrus in gilts. Theriogenology 78:147-152. DOI:10.1016/j.theriogenology.2012.01.030

Talukder S., Kerrisk KL., Ingenhoff L., Thomson PC., Garcia SC., Celi P. 2014. Infrared technology for estrus detection and as a predictor of time of ovulation in dairy cows in a pasture-based system. Theriogenology 81:925-935. DOI: 10.1016/j.theriogenology.2014.01.009.

R Core Team. 2016. R: A language and environment for statistical computing. R Foundation for Statistical Computing, Vienna, Austria. Available at: http. www. R-project. org.

Townsend SW., Deschner T., Zuberbühler K. 2008. Female Chimpanzees Use Copulation Calls Flexibly to Prevent Social Competition. PLoS ONE 3:e2431. DOI: 10.1371/journal.pone.0002431. 
520 Townsend SW., Deschner T., Zuberbühler K. 2011. Copulation calls in female chimpanzees (Pan

521 troglodytes schweinfurthii) convey identity but do not accurately reflect fertility. International 522 Journal of Primatology 32:914-923. DOI:10.1007/s10764-011-9510-2

523 Travain T., Colombo ES., Grandi LC., Heinzl E., Pelosi A., Previde EP., Valsecchi P. 2016. How good is 524 this food? A study on dogs' emotional responses to a potentially pleasant event using infrared thermography. Physiology \& Behavior 159:80-87. DOI:10.1016/j.physbeh.2016.03.019

526 Travain T., Colombo ES., Heinzl E., Bellucci D., Previde EP., Valsecchi P. 2015. Hot dogs:

527 Thermography in the assessment of stress in dogs (Canis familiaris) - A pilot study. Journal of

$528 \quad$ Veterinary Behavior: Clinical Applications and Research 10:17-23.

$529 \quad$ DOI:10.1016/j.jveb.2014.11.003

530 Tutin CEG. 1975. Sexual behaviour and mating patterns in a community of wild chimpanzees (Pan troglodytes schweinfurthii). Ph.D. Thesis, University of Edinburgh

Wallis J. 1982. Sexual behavior of captive chimpanzees (Pan troglodytes): Pregnant versus cycling females. American Journal of Primatology 3:77-88. DOI: 10.1002/ajp.1350030107.

Wallis J. 1992. Chimpanzee genital swelling and its role in the pattern of sociosexual behavior. American Journal of Primatology 28:101-113. DOI: 10.1002/ajp.1350280203.

Wallis J., Goodall J. 1993. Anogenital swelling in pregnant chimpanzees of Gombe National Park. American Journal of Primatology 31:89-98. DOI: 10.1002/ajp.1350310202.

Watts DP., Mitani JC. 2000. Infanticide and cannibalism by male chimpanzees at Ngogo, Kibale National Park, Uganda. Primates 41:357-365. DOI:10.1007/BF02557646

Williams JM., Lonsdorf EV., Wilson ML., Schumacher-Stankey J., Goodall J., Pusey AE. 2008. Causes

Wilson ML., Boesch C., Fruth B., Furuichi T., Gilby IC., Hashimoto C., Hobaiter CL., Hohmann G., Itoh N., Koops K., Lloyd JN., Matsuzawa T., Mitani JC., Mjungu DC., Morgan D., Muller MN., Mundry R., Nakamura M., Pruetz J., Pusey AE., Riedel J., Sanz C., Schel AM., Simmons N., 
546 Waller M., Watts DP., White F., Wittig RM., Zuberbühler K., Wrangham RW. 2014. Lethal 547 aggression in Pan is better explained by adaptive strategies than human impacts. Nature 513:414548 417. DOI: $10.1038 /$ nature13727.

549 Ziegler TE., Epple G., Snowdon CT., Porter TA., Belcher AM., Küderling I. 1993. Detection of the 550 chemical signals of ovulation in the cotton-top tamarin, Saguinus oedipus. Animal Behaviour $551 \quad$ 45:313-322. DOI: 10.1006/anbe.1993.1036.

552

553 


\section{FIGURE CAPTIONS}

555 Figure 1 Example of an IRT measurement. The polygon is drawn around the left ear of the

556 individual, which can be seen lying on the ground.

557 Figure 2 Model results for differences in skin surface temperature. Shown is the interaction

558 between swelling stage and pregnancy status, with model estimates and associated 95\%

559 confidence intervals back-transformed to the original scale (for modelling, surface temperature

560 was squared, see Supplementary Information).

561 Figure 3 Model predictions for skin surface temperature of female chimpanzees per body part

562 for non-pregnant and pregnant females. The temperature axis shows values back-transformed to 563 the original scale (for modelling, surface temperature was squared, see Supplementary 564 Information).

565 Figure 4 Median skin surface temperature with 25\% and 75\% quartiles, of female chimpanzees 566 per body part for non-pregnant and pregnant females. In contrast to Figures 2 and 3, we show 567 untransformed raw data here (see Supplementary Information). 


\section{TABLES}

571 Table 1 Distribution of images per female (ID) and by reproductive condition (Non-pregnant 572 and Pregnant).

573 Table 2 Results of full model. Reference level for pregnancy was 'Non-pregnant' and for 574 swelling stage ' 0 '. $t$ values for main effects comprised in interactions are omitted. 


\section{Figure 1}

Example of IRT measurement.

The polygon is drawn around the left ear of the individual which can be seen laying on the ground.
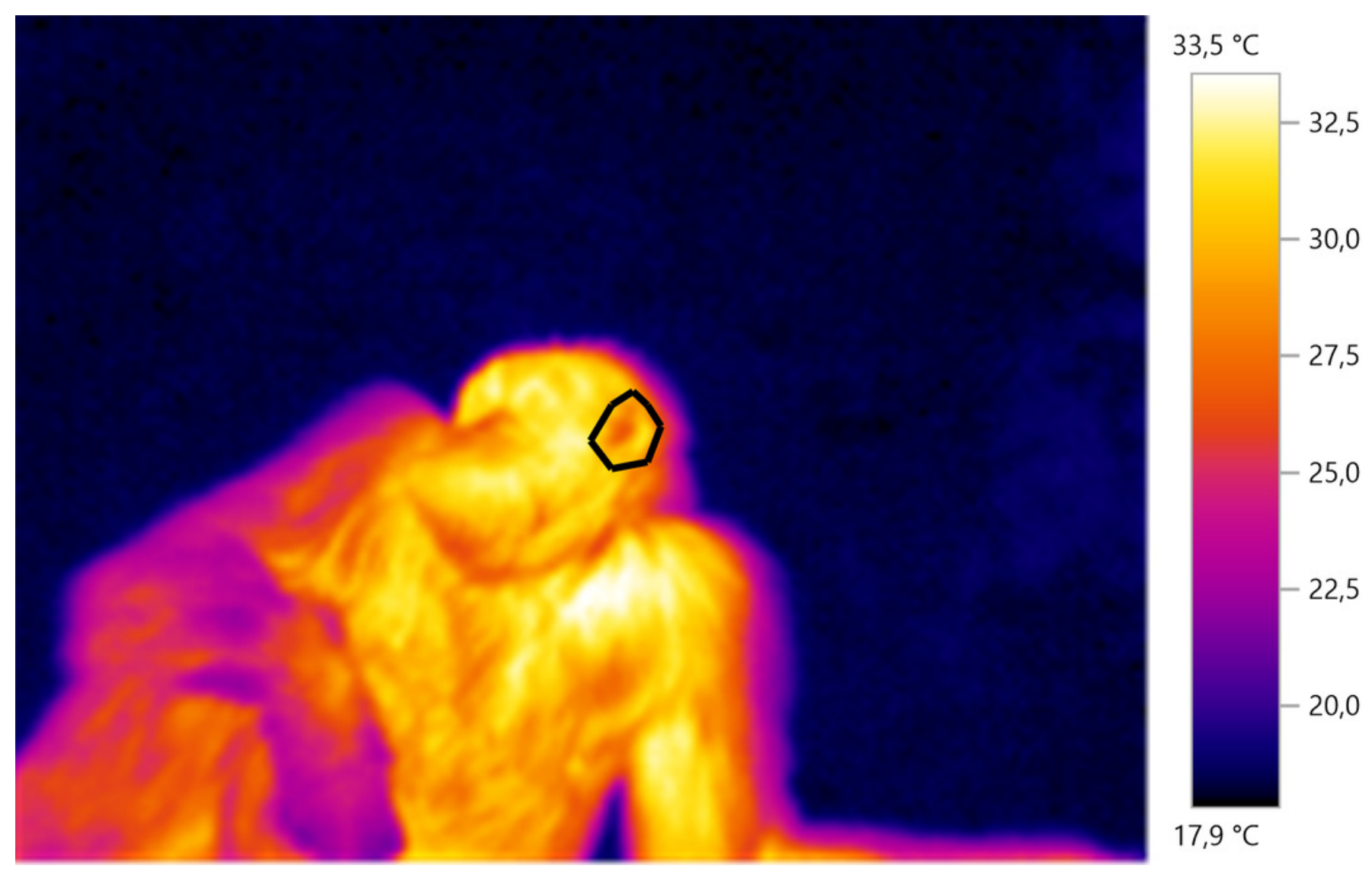


\section{Figure 2 (on next page)}

Model results for differences in body surface temperature.

Shown is the interaction between swelling stage and pregnancy status, with model estimates and associated $95 \%$ confidence intervals back-transformed to the original scale (for modeling, surface temperature was squared, see supplementary information). 


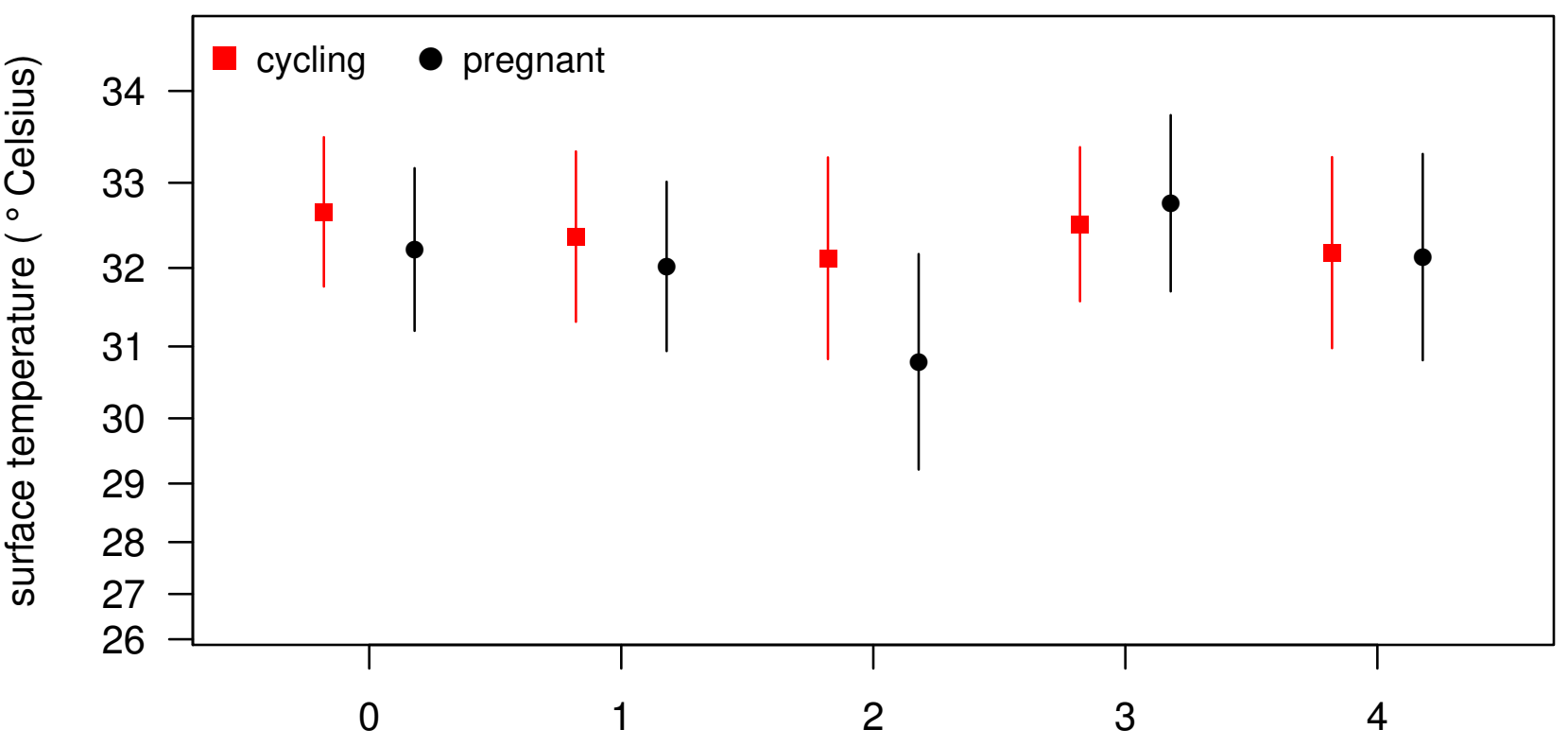

\section{swelling stage}




\section{Figure 3 (on next page)}

Model predictions for surface temperature of female chimpanzees per body part for non-pregnant and pregnant females.

The temperature axis shows values back-transformed to the original scale (for modeling, surface temperature was squared, see supplementary information). 


\section{Figure 4 (on next page)}

Median surface temperature with $25 \%$ and $75 \%$ quartiles, of female chimpanzees per body part for non-pregnant and pregnant females.

In contrast to figure 2 and 3 , we show untransformed raw data here (see supplementary information). 


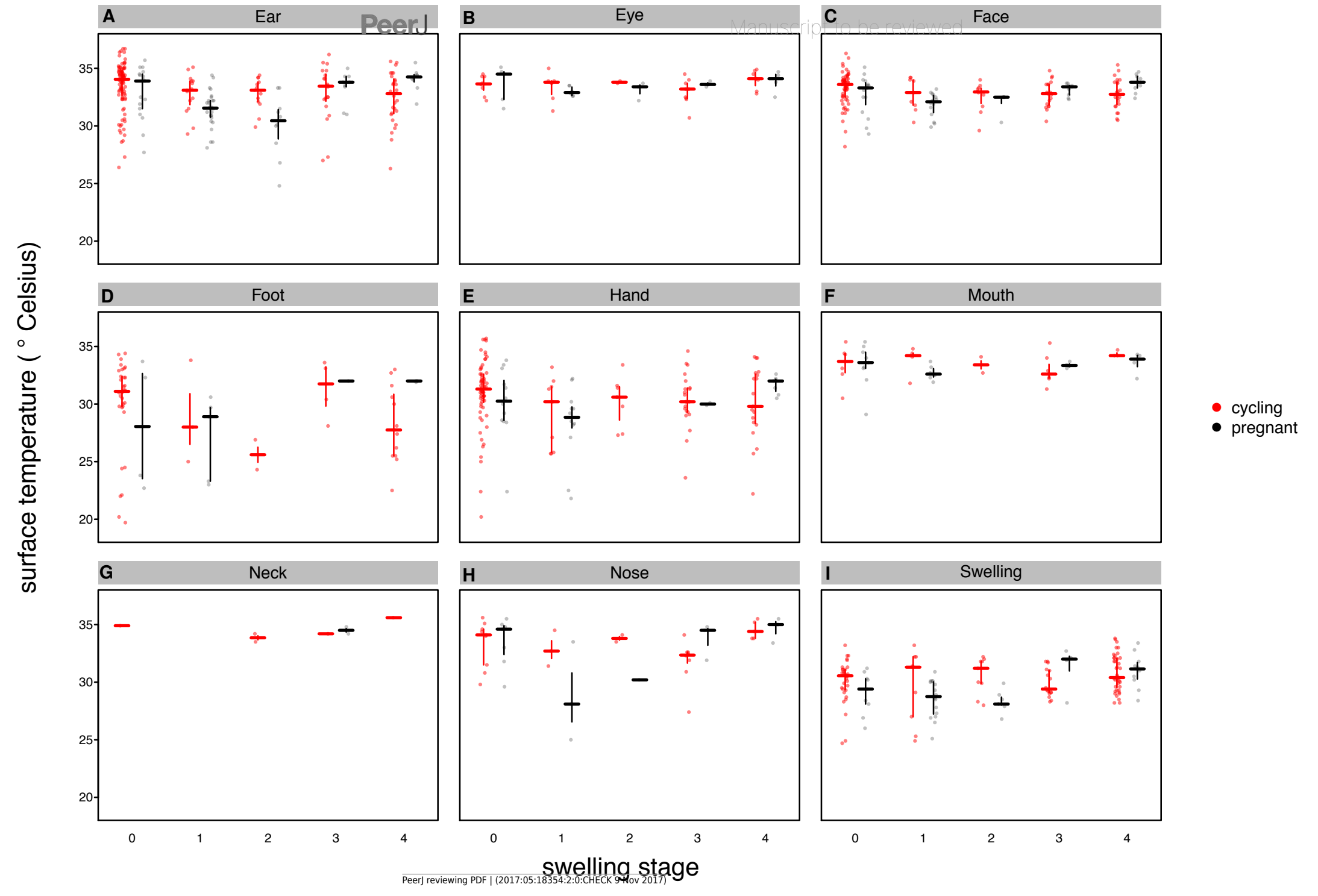




\section{Table $\mathbf{1}$ (on next page)}

Distribution of images per female (ID) and by reproductive condition (non-pregnant and pregnant). 


\begin{tabular}{|c|c|c|}
\hline Female ID & Non-pregnant & Pregnant \\
\hline $\mathrm{AN}$ & 9 & \\
\hline HL & 3 & \\
\hline IN & 2 & \\
\hline $\mathrm{JN}$ & 61 & 58 \\
\hline JT & 39 & \\
\hline KA & 5 & \\
\hline KL & 24 & 55 \\
\hline KM & 6 & \\
\hline $\mathrm{KN}$ & 19 & \\
\hline $\mathrm{KR}$ & 40 & \\
\hline KU & 4 & 72 \\
\hline KW & 52 & \\
\hline KY & 38 & \\
\hline ML & 38 & \\
\hline $\mathrm{MN}$ & 6 & \\
\hline NB & 100 & \\
\hline NT & 100 & \\
\hline OK & 68 & 91 \\
\hline RH & 12 & \\
\hline $\mathrm{RS}$ & 29 & \\
\hline Total & 655 & 276 \\
\hline
\end{tabular}

1 


\section{Table 2 (on next page)}

Results of full model.

Reference level for pregnancy was 'not pregnant' and for swelling stage ' 0 '. $t$ values for main effects comprised in interactions are omitted. 
Parameter estimate $\quad$ Standard error $\quad t$ value

\begin{tabular}{|c|c|c|c|c|}
\hline Intercept & & 168.15 & 11.44 & 14.70 \\
\hline Swelling stage 1 & & -7.44 & 6.91 & \\
\hline Swelling stage 2 & & -13.94 & 7.77 & \\
\hline Swelling stage 3 & & -3.72 & 5.38 & \\
\hline Swelling stage 4 & & -12.26 & 6.52 & \\
\hline Pregnancy & & -11.32 & 6.33 & \\
\hline Ambient temperatur & & 29.65 & 2.17 & 13.69 \\
\hline Distance & & -4.66 & 1.38 & -3.37 \\
\hline Humidity & & -4.89 & 2.21 & -2.21 \\
\hline $\begin{array}{l}\text { Swelling stage } \\
\text { pregnancy }\end{array}$ & 1: & 2.36 & 8.98 & 0.26 \\
\hline $\begin{array}{l}\text { Swelling stage } \\
\text { pregnancy }\end{array}$ & 2: & -19.81 & 10.82 & -1.83 \\
\hline $\begin{array}{l}\text { Swelling stage } \\
\text { pregnancy }\end{array}$ & 3: & 17.62 & 10.32 & 1.71 \\
\hline $\begin{array}{l}\text { Swelling stage } \\
\text { pregnancy }\end{array}$ & 4: & 9.98 & 9.30 & 1.07 \\
\hline
\end{tabular}


1

Peer] reviewing PDF | (2017:05:18354:2:0:CHECK 9 Nov 2017) 